\title{
An Application Method of Free Burn HRR Data to Room Fire Scenarios
}

\author{
YUSUKE SHINTANI ${ }^{1}$, TSUTOMU NAGAOKA ${ }^{1}$, YOSHIKAZU DEGUCHI ${ }^{1}$ and KAZUNORI \\ HARADA $^{2}$ \\ ${ }^{1}$ Research and Development Institute \\ Takenaka Corporation \\ 1-5-1, Ohtsuka, Inzai, Chiba, Japan \\ ${ }^{2}$ Department of Architecture and Architectural Engineering, \\ Kyoto University \\ Kyotodaigaku katsura, Nishikyo-ku, Kyoto, Japan
}

\begin{abstract}
An application method of free burn heat release rate (HRR) data for a single seater sofa to predict the burning behavior in a compartment is proposed. A single seater sofa was burnt in an open environment to measure the HRR using a furniture calorimeter. The time-HRR curve was fitted with a model of burning of a cubic polyurethane block developed earlier. The model included the flame spread over horizontal, downward and lateral directions. The flame spread rates were increased if the block received radiative heat from external heat sources other than from the flame. The thermal radiation feedback from the flame, smoke layer, and heated wall surfaces was coupled with the burning model. Using the coupled model, the burning and spread rate of several sofas and a table in a small compartment was calculated and compared with experimental results. The model could reproduce the trend for the increase in HRR qualitatively. However, the time to spread to an adjacent object was not in good agreement. If the time to spread was given input to the model, other parameters such as compartment temperature and so on could be calculated with reasonable agreement.
\end{abstract}

KEYWORDS: heat release rate, modeling, compartment fires, fire spread, real combustibles

\section{NOMENCLATURE}

\begin{tabular}{|c|c|c|c|}
\hline & $T_{i g}$ & ignition temperature $[\mathrm{K}]$ \\
\hline \multicolumn{2}{|c|}{$A \quad$ burning area $\left[\mathrm{m}^{2}\right]$, surface area $\left[\mathrm{m}^{2}\right]$} & $T_{h, p}$ & surface temperature at ignition $[\mathrm{K}]$ \\
\hline$A_{o}$ & opening area $\left[\mathrm{m}^{2}\right]$ & $v_{c}$ & spread rate of melting core $[\mathrm{mm} / \mathrm{s}]$ \\
\hline$E$ & radiant emittance $\left[\mathrm{kW} / \mathrm{m}^{2}\right]$ & $v_{m h}$ & horizontal flame spread rate $[\mathrm{mm} / \mathrm{s}]$ \\
\hline$F$ & shape factor [-] & $v_{m h, p}$ & $\begin{array}{l}\text { horizontal flame spread of subsequent } \\
\text { item }\end{array}$ \\
\hline$H_{o}$ & opening height $[\mathrm{m}]$ & $v_{m d}$ & downward flame spread rate $[\mathrm{mm} / \mathrm{s}]$ \\
\hline$\Delta H_{\text {air }}$ & $\begin{array}{l}\text { heat of combustion per unit consumption } \\
\text { of air }[\mathrm{kJ} / \mathrm{kg}]\end{array}$ & $v_{m l}$ & lateral flame spread rate $[\mathrm{mm} / \mathrm{s}]$ \\
\hline$\Delta H_{c}$ & heat of combustion $[\mathrm{kJ} / \mathrm{kg}]$ & Gree & letters \\
\hline$L$ & flame height $[\mathrm{m}]$ & $\chi$ & radiative fraction $[-]$ \\
\hline$\Delta L_{v}$ & heat of vaporization $[\mathrm{kJ} / \mathrm{kg}]$ & $\varepsilon_{f}$ & emissivity of flame [-] \\
\hline$m_{\text {in }}$ & incoming mass flow rate of air $[\mathrm{kg} / \mathrm{s}]$ & Subs & ripts \\
\hline$m_{f, \infty}^{\prime \prime}$ & burning rate per unit area $\left[\mathrm{kg} /\left(\mathrm{m}^{2} \cdot \mathrm{s}\right)\right]$ & $a$ & ambient air \\
\hline$Q$ & heat release rate[kW] & $c$ & continuous flame region \\
\hline$q$ ", & radiation heat flux $\left[\mathrm{kW} / \mathrm{m}^{2}\right]$ & $d$ & downward \\
\hline$q_{b}$ & re-radiation from burning surface $\left[\mathrm{kW} / \mathrm{m}^{2}\right]$ & $f$ & Flame \\
\hline$q_{c}$ & heat release rate per unit area $\left[\mathrm{kW} / \mathrm{m}^{2}\right]$ & $h$ & horizontal surface \\
\hline$q_{e}$ & external radiation $\left[\mathrm{kW} / \mathrm{m}^{2}\right]$ & $i$ & intermittent flame region \\
\hline$q_{f c}$ & radiation emittance from flame $\left[\mathrm{kW} / \mathrm{m}^{2}\right]$ & $t$ & Table \\
\hline$T$ & temperature $[\mathrm{K}]$ & $v$ & vertical surface \\
\hline
\end{tabular}




\section{INTRODUCTION}

Prediction of burning behavior in buildings is one of the important steps in performance-based fire safety design. Using heat release rate (HRR) data of real combustibles is one of the ways to predict the behavior. Therefore HRR of many real combustible objects have been measured with a furniture calorimeter e.g. [1,2]. Most furniture tests have been carried out in an open atmosphere. Test results are used mainly for classification purposes. Direct use of furniture calorimeter data in building design is acceptable if the compartment is large enough so that the burning behavior is similar to that in the open atmosphere. In the case of normal size rooms, the burning is intensified [3] as the burning item receives thermal radiation feedback from the smoke layer, room surfaces and flames from other burning items, if any. Thus it is not recommended to use furniture calorimeter data directly as input to building fire safety design. However, a method to predict the burning behavior of furniture in a compartment from the data measured by the furniture calorimeter has not been established yet.

In the case of a pool fire, Ustikul et al. [4] and Goto et al. [5] proposed methods of predicting the burning behavior considering compartment effects. The mass loss rate is increased by radiation feedback from the smoke layer and decreased by oxygen depletion. However, the application to realistic objects still needs to be discussed. For example, Kim et al. [6] used a CFD model to predict the fire behavior in a small compartment and found significant differences with experimental results. Providing all input data for material properties is also difficult.

The purpose of this study was to propose a method of predicting the burning behavior of real combustibles in a compartment using HRR data measured in the furniture calorimeter. A single seater sofa was burnt in a furniture calorimeter. Then the measured HRR - time history was fitted to a simple model of burning behavior of a polyurethane block [7]. Using the burning model together with a zone fire model for a single compartment [8], the effects of radiation feedback was calculated. The calculated results were compared with a fire spread experiment in a compartment containing three sofas and one wooden table.

\section{SCHEMATICS OF BURNING MODEL AND COMPARTMENT FIRE MODEL}

\section{Burning model of a cubic polyurethane block}

The original burning model was proposed by Tsukuda et al. [9] to predict flame spread and the change of shape due to the burning of a cubic polyurethane block. Fig.1 shows the outline of the model. The burning process was modeled as follows; a) The flame spreads concentrically over the top surface after being ignited. The horizontal flame spread rate $v_{m h}$ was calculated by considering the heat flux from the flame to a preheated zone, $F_{f} q_{f c}$, where $F_{f}$ is shape factor of the flame, and $q_{f c}$ is the radiant emittance from flame. The melting core beneath the flame spreads in horizontal and downward directions at the rates $v_{c h}$ and $v_{c d}$ respectively. b) When the flame spread front arrives at the edge of the horizontal surface, flame spreads vertically downward over side surfaces at the rate of $v_{m d}$. After the ignited piece of material dripped to the bottom, upward and lateral flame spread takes place over side surface. The upward spread rate was assumed infinite, while the lateral flame spread rate is denoted by $v_{m l} . \mathrm{c}$ ) After the flame spread to the all surfaces, size of all surfaces are reduced until burnt out.

The time history for the burning area on each surface were calculated by the flame spread calculations outlined above. As a result, the horizontal burning surface area $A_{h}$ and vertical burning surface area $A_{v}$ were calculated for each time step. The HRR was calculated by multiplying the HRR per unit area by the applicable surface area (for horizontal surface $q_{c h}$; for vertical surface $q_{c v}$ ).

$$
Q=q_{c h} \times A_{h}+\Sigma q_{c v} \times A_{v}
$$

These parameters were calibrated to predict the time history of HRR of polyurethane blocks of the following sizes ${ }^{\mathrm{W}} 500 \mathrm{x}^{\mathrm{D}} 500 \mathrm{x}^{\mathrm{H}} 500 \mathrm{~mm}, 1000 \times 1000 \times 500 \mathrm{~mm}, 500 \times 500 \times 1000 \mathrm{~mm}$ in open air [9].

The original model was intended for burning in an open environment, where no radiation feedback is received. Thus the model was extended by Shintani et al. [7] to consider radiation feedback in compartment. The calculation parameters were revised to include the enhancement by radiation from smoke layers as shown in Table 1. Here, $q_{e h}$ and $q_{e v}$ are the radiation feedback fluxes to the horizontal and vertical surfaces respectively. The formulae were validated by comparison with experiments carried out under smoke layers of various heights. In the experiments, two sizes of polyurethane block $\left({ }^{\mathrm{W}} 350 \mathrm{x}^{\mathrm{D}} 350 \mathrm{x}^{\mathrm{H}} 350 \mathrm{~mm}\right.$ and 
$600 \times 600 \times 350 \mathrm{~mm})$ were burned in a small compartment $\left({ }^{\mathrm{W}} 2700 \mathrm{x}^{\mathrm{D}} 2700 \mathrm{x}^{\mathrm{H}} 560-1200 \mathrm{~mm}\right)$. The ceiling height was changed so that smoke layer temperature varied in the range 100 to $500^{\circ} \mathrm{C}$, which corresponds to different levels of radiative heat flux to the urethane block surfaces. The revised model predicts burning behavior of polyurethane blocks in a small compartment fairly well.

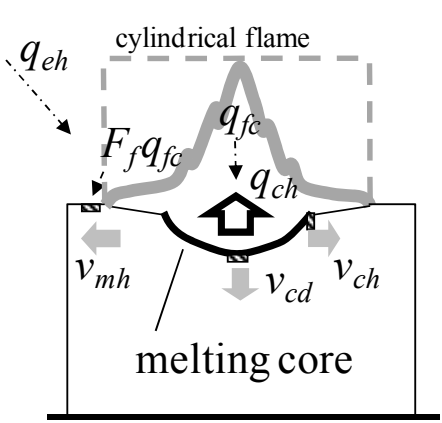

a) Flame spread over the top surface

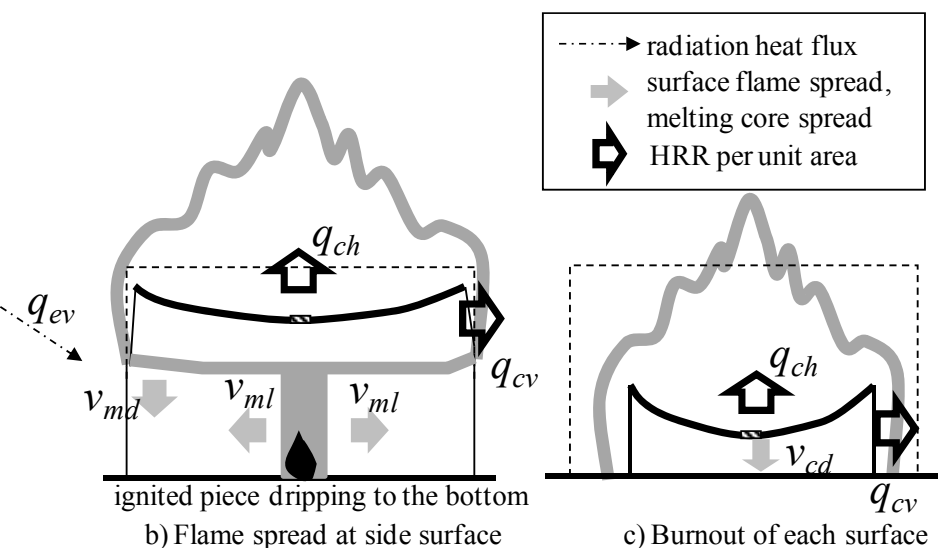

c) Burnout of each surface

Fig.1 Burning model of a cubic polyurethane block [9]

Table 1 Input parameters for the burning model with radiation feedback

\begin{tabular}{|l|l|}
\hline Parameter & for urethane cuboid [7] \\
\hline \hline$q_{c h}\left[\mathrm{~kW} / \mathrm{m}^{2}\right]$ & $\left(q_{f c}+\left(1-\varepsilon_{f}\right) q_{e h}-q_{b}\right) / \Delta L_{v} \times \Delta H_{c}$ \\
\hline$\Delta L_{v}[\mathrm{~kJ} / \mathrm{kg}]$ & 1220 \\
\hline$q_{c v}\left[\mathrm{~kW} / \mathrm{m}^{2}\right]$ & $225+q_{e v} / 1.28 \times \Delta H_{c}$ \\
\hline$v_{m h}[\mathrm{~mm} / \mathrm{s}]$ & $0.0133\left(F_{f} q_{f c}+F_{f}\left(1-\varepsilon_{f}\right) q_{e h}+\left(1-F_{f}\right) q_{e h}\right)^{2}+2.66$ \\
\hline$v_{m d}[\mathrm{~mm} / \mathrm{s}]$ & $1.97+2.24 q_{e v}$ \\
\hline$v_{m l}[\mathrm{~mm} / \mathrm{s}]$ & $2.91+2.24 q_{e v}$ \\
\hline
\end{tabular}

\section{Pre-flashover compartment fire model with fire spread between items}

A two-layer zone model was used to calculate the smoke layer development in a compartment as developed by Tanaka et al.[10], but modified to include the spatial distribution of wall surface temperatures [8]. As shown in Fig.2, the internal surfaces were divided into rectangular elements of similar scale to the combustible items. The temperatures of each element were calculated assuming one dimensional transient heat conduction. For the radiation exchange, the radiative component of the HRR was distinguished from the total HRR and distributed to the elements. Then the inter-reflection between surfaces was calculated using a radiation network system.

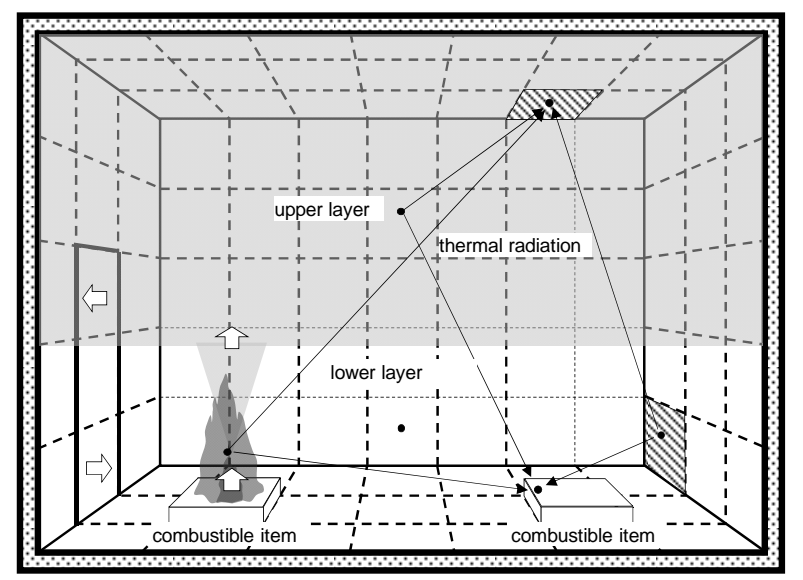

Fig.2 Pre-flashover compartment fire model with fire spread between items[8] 
The time to fire spread was predicted by calculating the surface temperature of the yet-to-burn combustible item assuming one dimensional heat conduction using the calculated incident heat flux from the flames, smoke layer and internal surface elements. When the surface temperature reaches the ignition temperature, the item is assumed to be ignited. After ignition of the second item, its burning is calculated in a similar way to first ignited item, however the flame spread rate is increased taking into account the effect of preheating. As the flame spread rate is inversely proportional to the square of the difference between the ignition temperature $T_{i g}$ and the surface temperature at ignition, the horizontal flame spread rate of the second and subsequent items, $v_{m h, p}$, is calculated by:

$$
v_{m h, p}=\frac{\left(T_{i g}-T_{a}\right)^{2}}{\left(T_{i g}-T_{h, p}\right)^{2}} v_{m h}
$$

Here, $T_{\mathrm{a}}$ is the ambient temperature and $T_{h, p}$ is the average surface temperature at ignition. The flame spread rates in other directions are increased in the same way.

\section{Post-flashover compartment fire model}

The two-layer zone model switches to a single-layer zone model when the calculated height of the smoke layer is less than $10 \%$ of the ceiling height. The mass flow rate and heat transfer are calculated in the same way as for the two-zone model. The HRR was calculated using the equation (3), assuming a ventilationcontrolled fire.

$$
Q=\Delta H_{\text {air }} m_{\text {in }}
$$

The mass burning rate of all the combustibles, $m_{f}$, was calculated using the conventional correlations [11] for a ventilation-controlled fire.

$$
m_{f}=0.1 A_{o} \sqrt{ } H_{o}
$$

\section{FITTING FURNITURE CALORIMETER DATA TO THE BURNING MODEL}

To obtain input for the calculation, a single seater sofa was burnt in a furniture calorimeter. The HRR data was fitted to the burning model. The same sofa was also used in the compartment fire experiment described later.

\section{Burning experiment of a single seater sofa}

The specimen was a single seater sofa with dimensions W690×D670×H650 mm. The seat height was 395 $\mathrm{mm}$ above floor. The cover was made of cotton with the cushion infill made of polyurethane foam and body made of rigid polystyrene foam. The sofa was ignited at the center of seating surface. The weight was $10.9 \mathrm{~kg}$.

The outline of the experimental setup is shown in Fig.3. The mass loss rate, HRR, centerline temperature profile, and heat flux to the surroundings were measured. The mass loss rate was measured using three load cells fitted beneath a loading platform. The HRR was measured using the oxygen consumption method. Centerline temperature profiles were measured at $500-\mathrm{mm}$ intervals from the seating surface using thermocouples. The radiation heat flux was measured using heat flux gauges placed horizontally at a distance of $190 \mathrm{~mm}$ from both the armrests and $1500 \mathrm{~mm}$ from the center of the specimen.

The photographs of the specimen and the HRR history are shown in Fig.4. The HRR was measured by oxygen consumption up to $1,000 \mathrm{~kW}$. When fire effluent overflowed from the hood, exceeding the capacity of measurement system, the HRR was calculated by multiplying the mass loss rate with the heat of combustion $(25 \mathrm{MJ} / \mathrm{kg})$. 


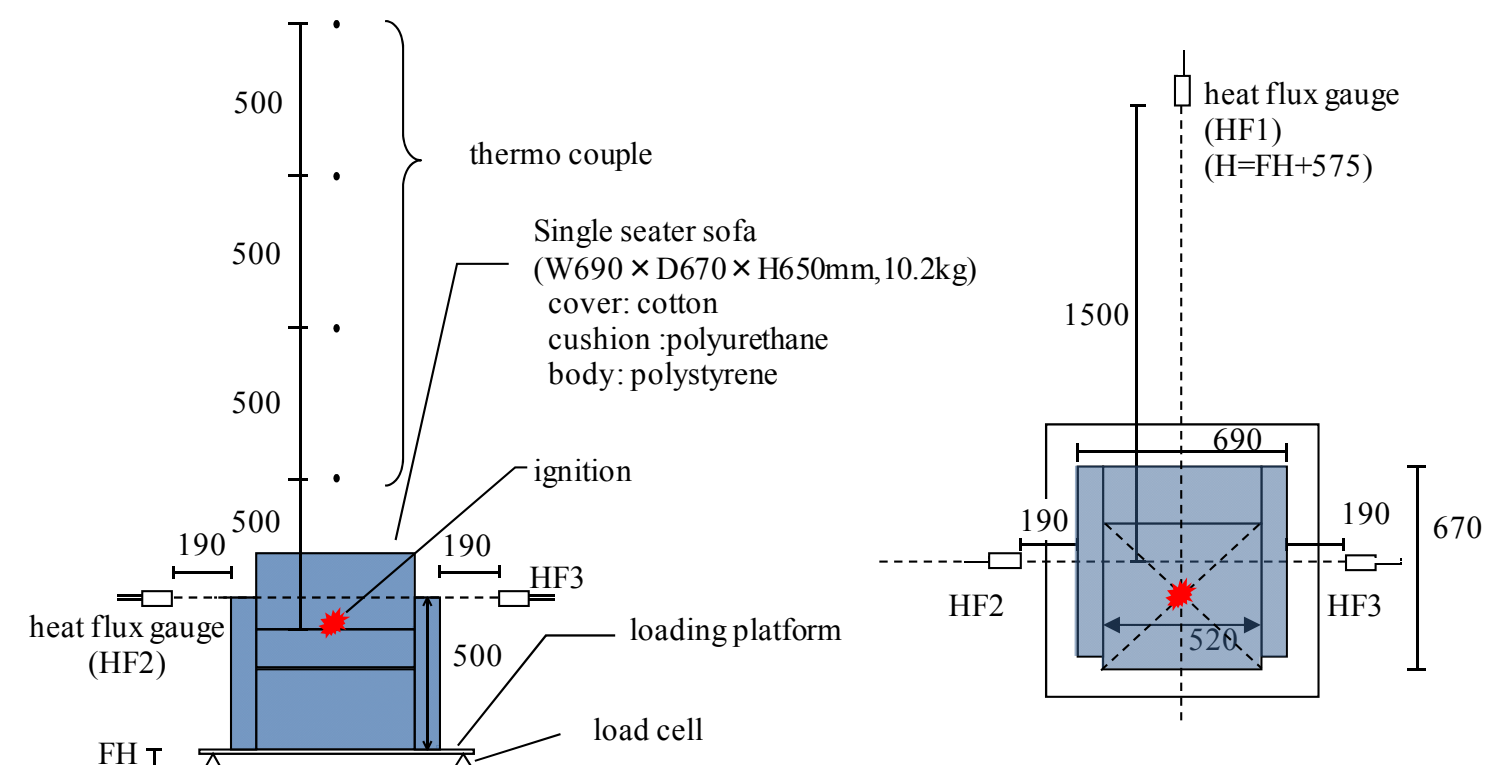

a) elevation

b) plan

Fig.3 Experimental setup for burning of a sofa in furniture calorimeter

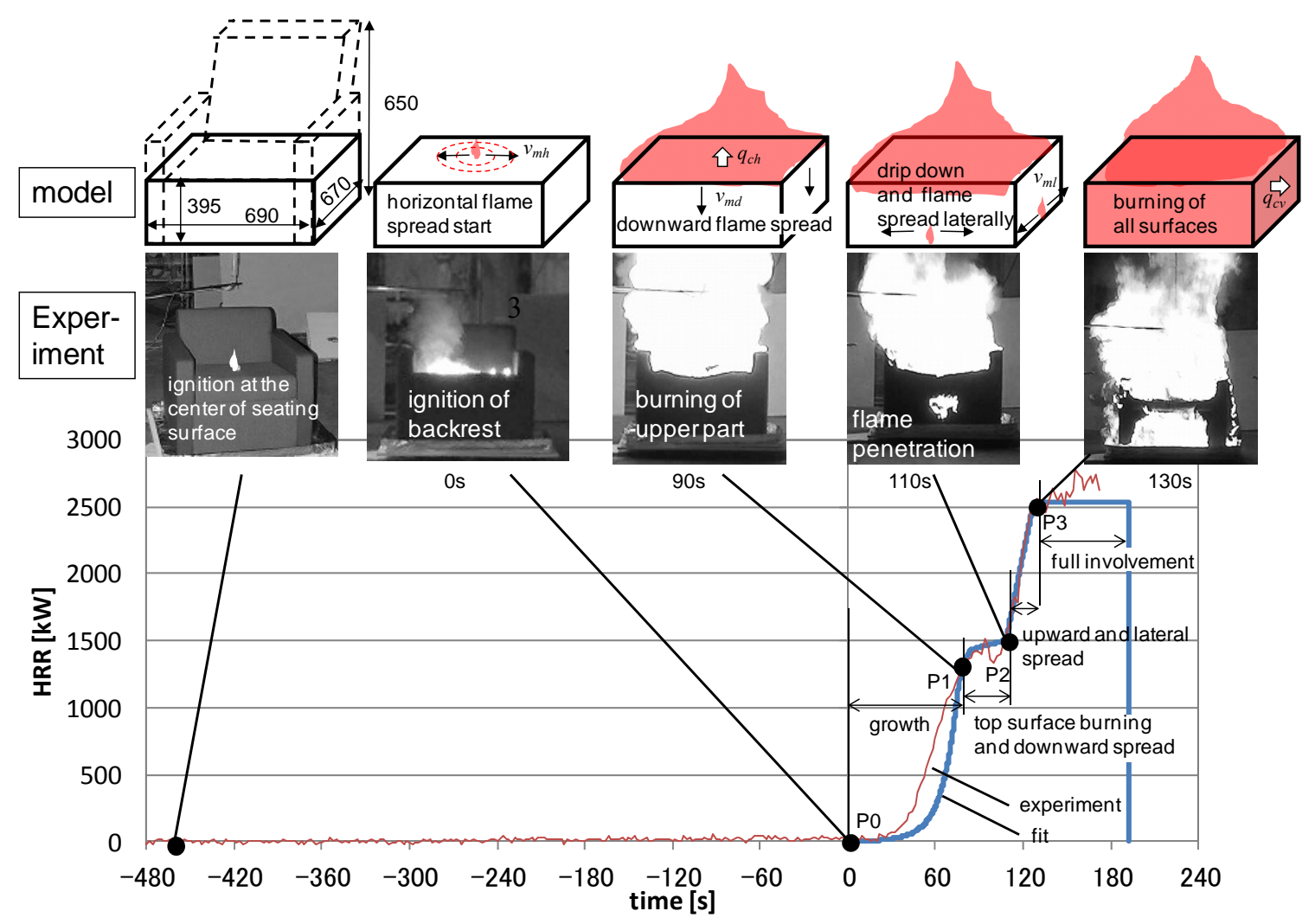

Fig.4 Fitting burning model to measured HRR of a single seater sofa in a furniture calorimeter 
After ignition, the cover and stuffing melted concentrically but the flame was confined under the cover until the flame reached to the edge. The HRR during this process was quite small but increased rapidly after spreading to the backrest. Thus the time origin was set at the moment of the flame spread to the backrest, namely, $460 \mathrm{~s}$ after the start of the experiment. At $90 \mathrm{~s}$, the burning area spread to the total armrest. All the upper part of the sofa was involved with flame and the HRR reached $1,400 \mathrm{~kW}$. After that, the increase in HRR was more gradual. As the flame penetrated through the lower part at $110 \mathrm{~s}$, the HRR increased rapidly again. The maximum HRR was $2,500 \mathrm{~kW}$ at $130 \mathrm{~s}$ when all the parts were involved. At $170 \mathrm{~s}$, part of the sofa dropped off the loading platform and no further data was obtained. Until that time approximately $90 \%$ by weight had burnt.

\section{Model fitting method}

To fit the measured HRR data to the burning model, the sofa was approximated as a cubic block W690 $\times$ D670 $\times$ H395 mm. The size was selected to have the same outer dimension as the original sofa. Five input parameters for the burning model $\left(q_{c h}, q_{c v}, v_{m h}, v_{m d}, v_{m l}\right)$ were searched to fit the model output to the measured HRR data. The HRR data in Fig. 4 was divided into 4 phases. The growth phase (point 0 to 1 ), top surface burning and downward spread phase (point 1 to 2). After the flame penetration to the side surface (point 2), the upward and lateral spreading phase (point 2 to 3 ) and the full involvement phase (after point 3 ). The estimated parameters were summarized in Table 2, which were derived as follows:

1) HRR per unit area of the horizontal surface and the horizontal flame spread rate $\left(q_{c h}, v_{m h}\right)$ At point 1, flame has spread to just cover all the seating surface. The HRR per unit area of the horizontal surface was calculated by dividing the HRR at point 1 by the area of the seating surface.

$$
q_{c h}=1,400 / 0.462=3,028\left[\mathrm{~kW} / \mathrm{m}^{2}\right]
$$

By estimating the heat flux to the burning surface using the formula shown in Table 1, the heat of vaporization $\Delta L_{v}$ was estimated as $419 \mathrm{~kJ} / \mathrm{kg}$. The flame spread rate over the horizontal surface was adjusted so that the spread over the entire surface coincided with point 1 . The factor 0.8 was introduced to the formula shown in Table 1.

2) HRR per unit area of vertical surface $\left(q_{c v}\right)$

The difference in HRR between points $1(1400 \mathrm{~kW})$ and $3(2500 \mathrm{~kW})$ corresponds with the burning of the vertical surface. Dividing the difference in HRR by the area of vertical surface, the HRR per unit area of vertical surface was estimated as $1,020 \mathrm{~kW} / \mathrm{m}^{2}$.

3) Downward flame spread over vertical surface $\left(v_{m d}\right)$

The difference between points 1 and 2 corresponds to the increase in burning area during the downward flame spread phase. The increase in HRR was divided by HRR per unit area $\left(q_{c v}\right)$ to obtain the increase in the burning area, which yielded the downward flame spread rate.

4) Lateral flame spread over vertical surface $\left(v_{m l}\right)$

Flame spread laterally over the vertical surface from point $2(110 \mathrm{~s})$ to point $3(130 \mathrm{~s})$. The spread rate was derived from the distance between the point of the flame penetration (the center of the vertical surface) and the edge.

Table 2 Calculation parameters in the HRR model

\begin{tabular}{|c|c|}
\hline Parameter & Values fitted to sofa \\
\hline$q_{c h}\left[\mathrm{~kW} / \mathrm{m}^{2}\right]$ & $\left(q_{f c}+\left(1-\varepsilon_{f}\right) q_{e h}-q_{b}\right) / \Delta L_{v} \times \Delta H_{c}$ \\
\hline$\Delta L_{v}[\mathrm{~kJ} / \mathrm{kg}]$ & $\underline{419}$ \\
\hline$q_{c v}\left[\mathrm{~kW} / \mathrm{m}^{2}\right]$ & $\underline{1020}+q_{e v} / 1.28 \times \Delta H_{c}$ \\
\hline$v_{m h}[\mathrm{~mm} / \mathrm{s}]$ & $\begin{array}{l}\left(0.0133\left(F_{f} q_{f c}+F_{f}\left(1-\varepsilon_{f}\right) q_{e h}\right.\right. \\
\left.\left.\quad+\left(1-F_{f}\right) q_{e h}\right)^{2}+2.66\right) \times 0.8\end{array}$ \\
\hline$v_{m d}[\mathrm{~mm} / \mathrm{s}]$ & $\underline{0.97+2.24 q_{e v}}$ \\
\hline$v_{m l}[\mathrm{~mm} / \mathrm{s}]$ & $18+2.24 q_{e v}$ \\
\hline
\end{tabular}

The fitting result is shown in Fig.4. During the growth phase, the HRR increases exponentially as the burning model assumes that the horizontal flame spread rate depends on the flame size. On the other hand, the measurement results show a linear increase during the upward flame spread over the backrest surface. 
The difference in the flame spread mechanism resulted in this error, however after point 1 , the agreement is considered sufficient.

\section{Checking the radiation heat flux from the flame to surroundings}

The radiation heat flux from the flame is the dominant mechanism for the fire spread between combustibles. Thus the accuracy of radiation heat flux was assessed by calculating the heat flux using the modeled HRR value and the shape of the burning area shown in Fig.4. The results were compared with the experimental measurements.

The flame shape was approximated by two cylinders. Their diameters were the same as that of the burning area. Their height was the same as the continuous and mean flame heights as calculated by experimental correlations proposed by Hasemi [12]. The temperature of the continuous flame region was set to $820^{\circ} \mathrm{C}$ and the temperature of intermittent flame region was set to $704^{\circ} \mathrm{C}(977 \mathrm{~K})$, which is the fourth power average of the temperatures at the top of continuous flame region and at the mean flame height. The radiant emittances of each region $E\left(=\sigma T^{4}\right)$ were calculated from the temperature and the emissivity $\varepsilon_{f}$, which was derived considering the heat balance at the flame surface as follows:

$$
\varepsilon_{f}=\chi Q /\left(A_{\mathrm{c}} E_{\mathrm{c}}+A_{\mathrm{i}} E_{\mathrm{i}}\right)
$$

where, $\chi$ is the radiation fraction (=0.44 for polystyrene [13]), $Q$ is the HRR, and $A$ is the surface area of the cylinders.

The radiation heat flux incoming to the measuring point, $q$ ", was calculated by

$$
q^{\prime \prime}=\varepsilon_{f}\left(F_{\mathrm{c}} E_{\mathrm{c}}+F_{\mathrm{i}} E_{\mathrm{i}}\right)
$$

where $F_{\mathrm{c}}$ and $F_{\mathrm{i}}$ are the shape factors for the continuous flame region and intermittent flame region as shown on right side of Fig.5.

The calculations were carried out for the measuring points shown in Fig.3. The results are shown in Fig.5. The calculated values changed in the same manner with HRR shown in Fig. 4 because the flame shape and the emissivity depend on the HRR. The measured values at points HF2 and HF3 were almost the same because their distances from the specimen were the same. However, the measurement values at HF2 increased rapidly at $160 \mathrm{~s}$ because part of the specimen fell onto the heat flux gauge. The experimental results at HF1, HF2 and HF3 were predicted well by this model, and the accuracy of the prediction of the heat flux from the flame to the surroundings was validated.

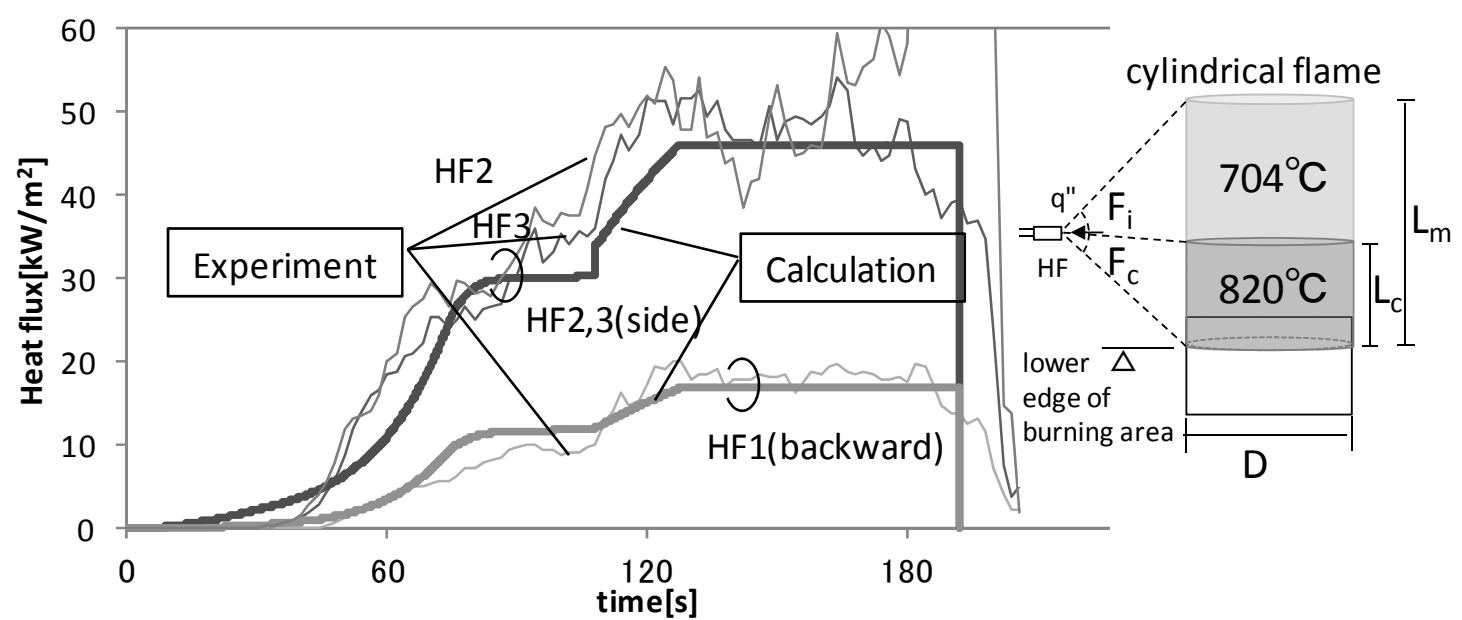

Fig.5 Radiation heat flux from experiment and calculation 
A full-scale compartment fire experiment was conducted for a mock-up of a reception room was conducted to compare the results with the calculation model.

The outline of the experimental setup is shown in Fig.6. The ceiling and a partition wall were built in a fire resistance furnace $\left({ }^{\mathrm{W}} 6000 \mathrm{x}^{\mathrm{D}} 3300 \mathrm{x}^{\mathrm{H}} 4500 \mathrm{~mm}\right)$ whose walls were composed of ceramic fiber blanket and the floor composed of a castable refractory. The ceiling height was 2,700 $\mathrm{mm}$ and the width and depth of the compartment were $3,300 \mathrm{~mm}$ each. The width and height of the openings at the center of the partition were 1,200 $\mathrm{mm}$ and 2,100 $\mathrm{mm}$, respectively. The ceiling was composed of rockwool insulation ( $9 \mathrm{~mm}$ thick), regular plasterboard (12.5 mm thick), and a metal frame. The partition was composed of two plasterboards with a thickness of $12.5 \mathrm{~mm}$ on each side of the light gauge steel frame. The walls and floor of the furnace as well as the side of the partition were exposed.

Two single seater sofas $\left({ }^{\mathrm{W}} 695 \mathrm{x}^{\mathrm{D}} 670 \mathrm{x}^{\mathrm{H}} 650 \mathrm{~mm}, 10.83 \mathrm{~kg}\right)$, a three seater sofa $\left({ }^{\mathrm{W}} 1728 \mathrm{x}^{\mathrm{D}} 670 \mathrm{x}{ }^{\mathrm{H}} 650 \mathrm{~mm}\right.$, $19.32 \mathrm{~kg})$, and a wooden table $\left({ }^{\mathrm{W}} 1190 \mathrm{x}^{\mathrm{D}} 590 \mathrm{x}^{\mathrm{H}} 393 \mathrm{~mm}, 13.96 \mathrm{~kg}\right)$ were placed in the compartment. The center of the seating surface of the single seater sofa, set near the opening, was ignited. The smoke flowed out of the opening and was exhausted through the duct which had one opening at $4000 \mathrm{~mm}$ above floor.

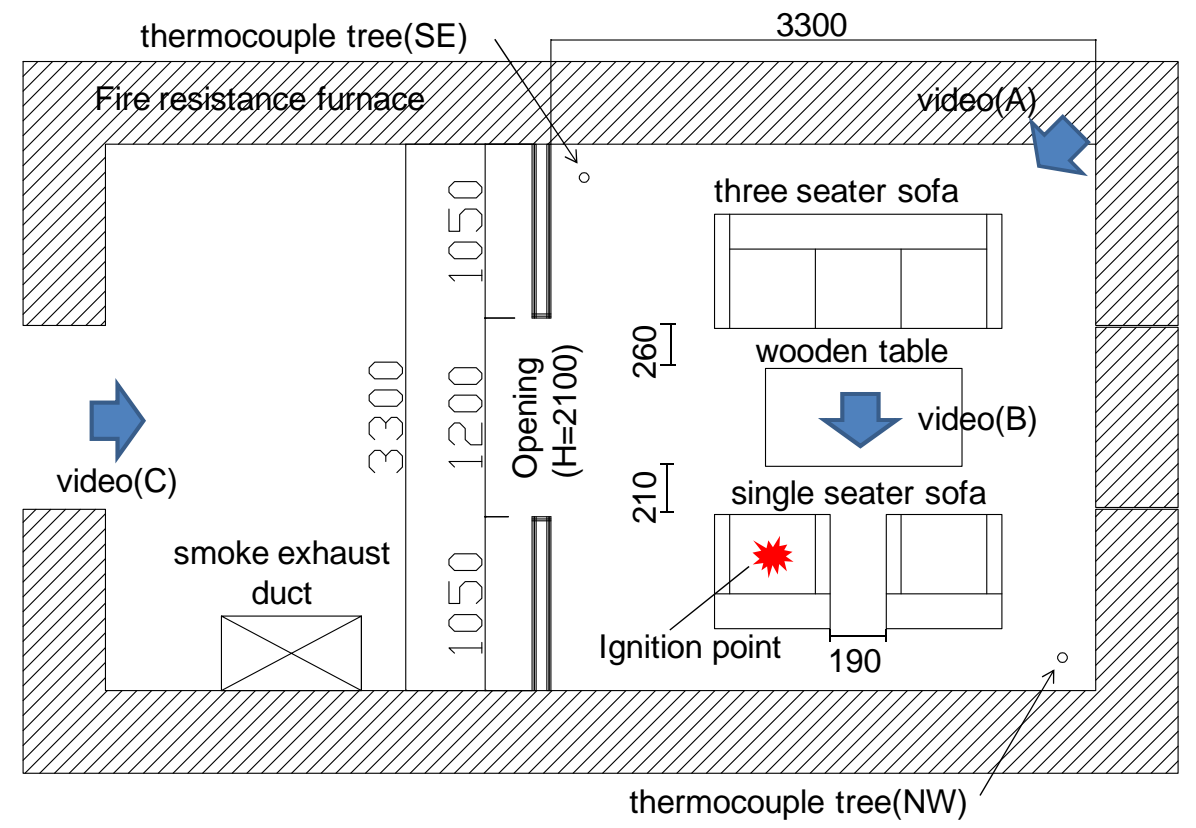

Fig.6 Outline of experimental setup (plan)

The temperatures measured by two thermocouple trees (SE: near the opening, NW: near the back wall) are shown in Fig.7. Some photographs taken by video cameras are shown in Fig.8. Flame spread to the backrest of the ignited sofa at 2 min 13s (Fig. 8a), after which the temperatures increased gradually. The

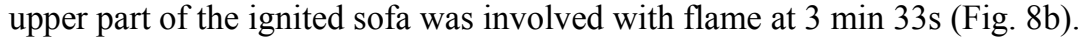

When the fire spread to the adjacent single seater sofa at $4 \mathrm{~min} 3 \mathrm{~s}$ (Fig. 8c), the temperature of the upper parts of the compartment was about $300^{\circ} \mathrm{C}$. Flame penetration through the lower part of the ignited sofa observed in the experiment conducted in open air as shown Fig.4 (point 2) did not occur until this time. The upper part of the sofa adjacent to the ignited sofa was involved with flame at 4 min $34 \mathrm{~s}$ (Fig. 8d) and flame spread rate of the sofa adjacent to the ignited sofa was faster than the sofa ignited at first.

The temperature of the upper layer was about $750{ }^{\circ} \mathrm{C}$ just before the fire spread to the three seater sofa at 5 min $8 \mathrm{~s}$ (Fig. 8e, flashover). The temperature of the lower layer increased rapidly and the compartment temperature became uniform at about $900^{\circ} \mathrm{C}$. All parts of the three seater sofa was involved with flame at 5 min $18 \mathrm{~s}$ (Fig.8f). The compartment temperature at thermocouple tree SE decreased rapidly after burning reduced at $8 \mathrm{~min}$, but the temperature at thermocouple tree NW decreased gradually. 


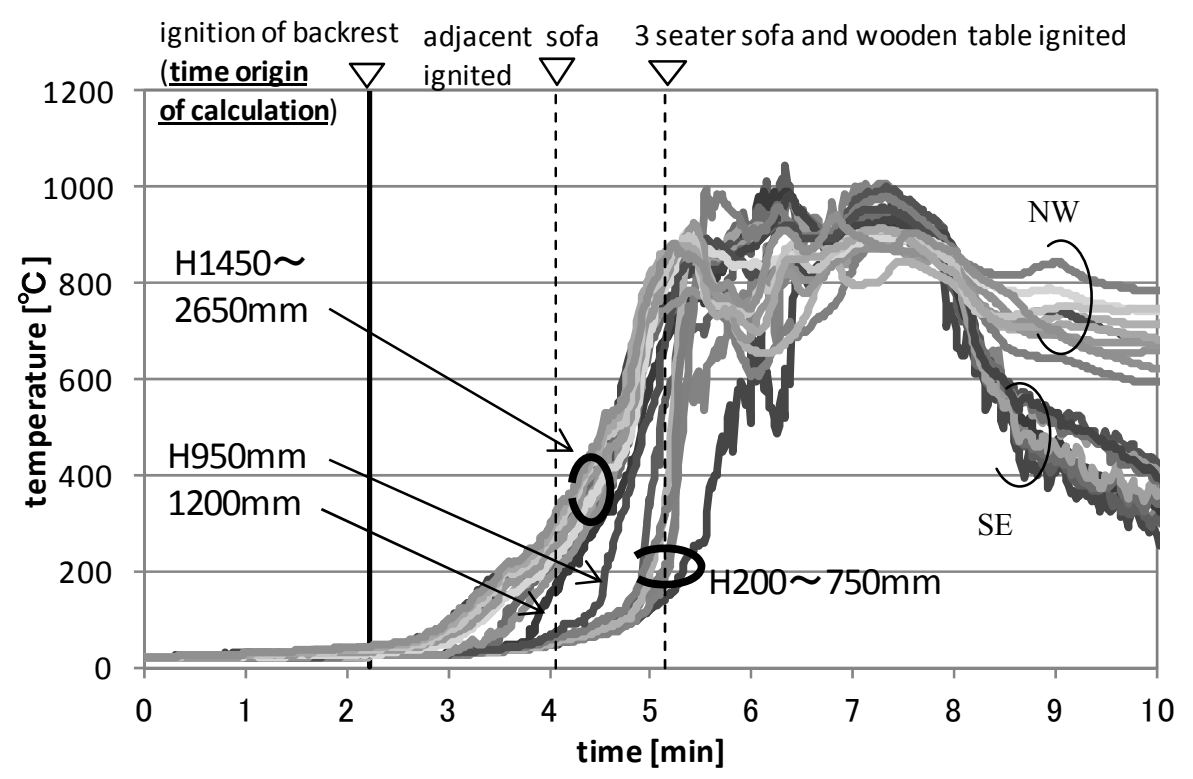

Fig.7 Compartment temperature measured by the thermocouple trees (SE, NW)

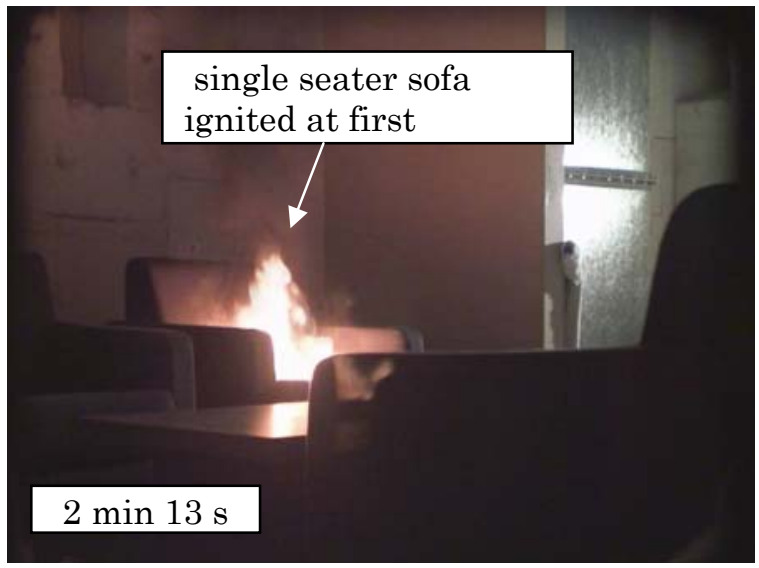

8a) Photograph by video camera(A) at $2 \min 13 \mathrm{~s}$

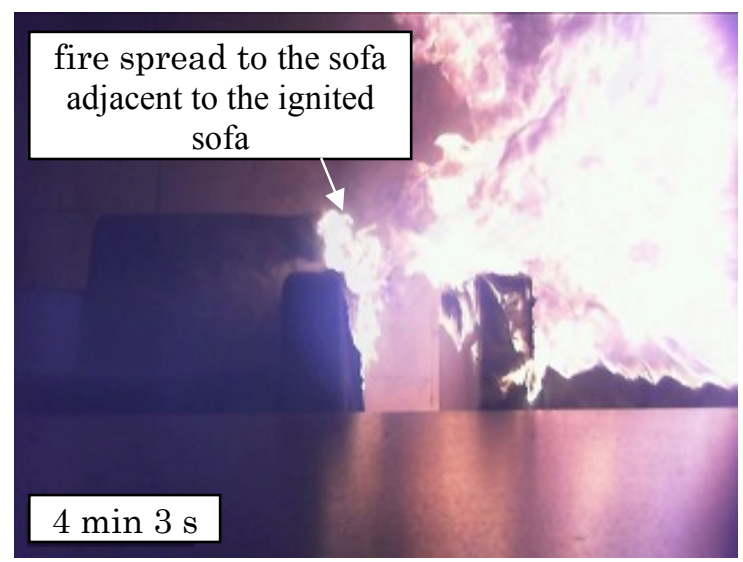

8c) Photograph by video camera(B) at $4 \min 3 \mathrm{~s}$

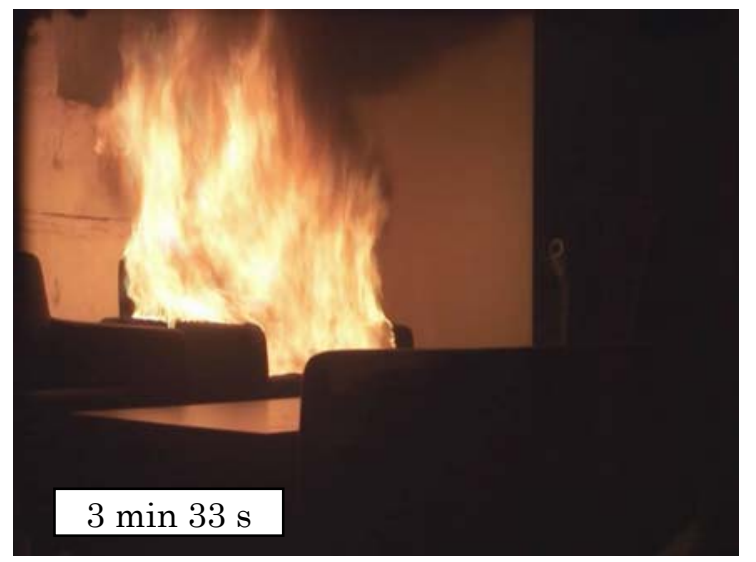

8b) Photograph by video camera(A) at $3 \min 33 \mathrm{~s}$

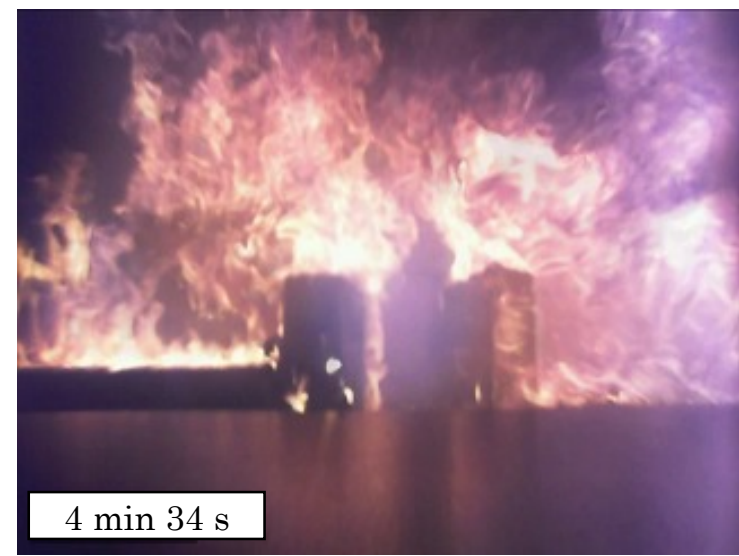

8d) Photograph by video camera(B) at $4 \min 34 \mathrm{~s}$ 


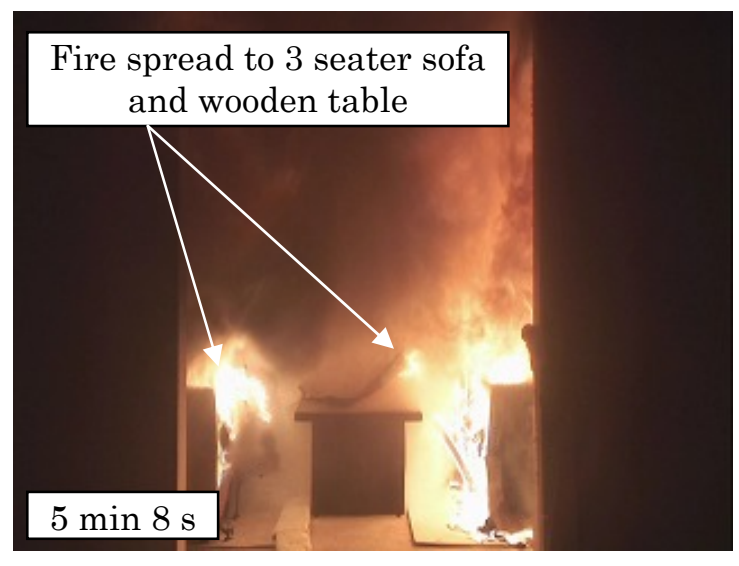

8e) Photograph by video camera $(\mathrm{C})$ at $5 \mathrm{~min} 8 \mathrm{~s}$

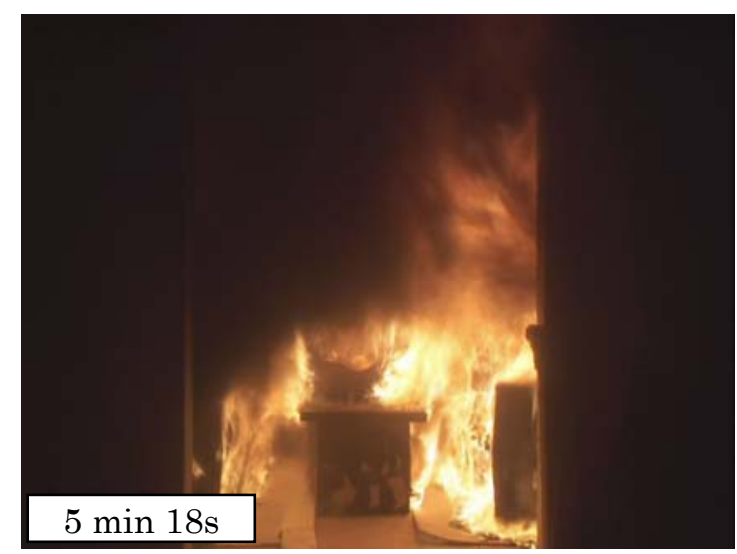

8f) Photograph by video camera(C) at $5 \min 18 \mathrm{~s}$

Fig.8 Photographs of the experiment

\section{COMPARISON WITH EXPERIMENTAL AND CALCULATION RESULTS}

\section{Calculation condition}

The fire development process between the three sofas in a small compartment was calculated by the burning model described above. The temperatures of the smoke layer, surface of combustibles and walls of compartment were calculated using the compartment fire model mentioned above. The HRR, burning rates, burning areas and shapes of the burning surfaces of each combustible objects were then substituted into the compartment fire model. The calculations were performed for two cases: i) considering radiation feedback from the smoke layer, warmed walls, etc. and ii) neglecting the radiation feedback. The calculation was started after the backrest of the single sofa ignited first ( 2 min $13 \mathrm{~s}$, shown in Fig. 8a). Because wooden combustibles were not considered by the burning model, the HRR of the wooden table $Q_{t}$ was calculated by simple correlation under the assumption that all surface areas burn simultaneously due to ignition after flashover in the experiment:

$$
Q_{t}=\left(m_{f, \infty}^{\prime \prime}+q_{e h} / \Delta L_{v}\right) \times A \times \Delta H_{c}
$$

where $m_{f, \infty}$ is the burning rate per unit area of table combustibles in open air $\left(=0.003 \mathrm{~kg} /\left(\mathrm{m}^{2} \cdot \mathrm{s}\right)[14]\right)$ and $A$ is the surface area.

Table 3 shows the calculation conditions and material properties of the walls and combustible objects. The compartment and opening were of the same size as in the experiments.

Table 3 Calculation conditions

\begin{tabular}{|c|c|}
\hline Parameter & Value \\
\hline \hline Size of compartment $(\mathrm{m})$ & $3.3 \times 3.3 \times 2.7$ \\
\hline Size of opening $(\mathrm{m})$ & $1.2 \times 2.1$ \\
\hline Thickness of wall/ ceiling / floor $(\mathrm{m})$ & $0.5 / 0.02 / 0.5$ \\
\hline Thermal conductivity of wall $/$ ceiling $/$ floor $(\mathrm{W} /(\mathrm{m} \cdot \mathrm{K}))$ & $0.12 / 0.16 / 1.2$ \\
\hline Density of wall/ ceiling / floor $\left(\mathrm{kg} / \mathrm{m}^{3}\right)$ & $100 / 863 / 2,200$ \\
\hline Specific heat of wall/ ceiling $/$ floor $(\mathrm{kJ} /(\mathrm{kg} \cdot \mathrm{K}))$ & $0.9 / 1.13 / 0.9$ \\
\hline Heat transfer coefficient of back face $\left.\left(\mathrm{kW} / \mathrm{m}^{2} \cdot \mathrm{K}\right)\right)$ & 0.008 \\
\hline Heat of combustion of sofa $/$ wooden table $(\mathrm{kJ} / \mathrm{kg})$ & $25000 / 16000$ \\
\hline Heat of decomposion of wooden table $\left(\Delta L_{v}, \mathrm{~kJ} / \mathrm{kg}\right)$ & 3000 \\
\hline Initial temperature $\left({ }^{\circ} \mathrm{C}\right)$ & 20 \\
\hline
\end{tabular}




\section{Calculation results}

The calculated compartment temperatures considering and neglecting radiation feedback are shown as solid and dashed lines, respectively, in Fig.9. The experimental results of the temperature measured above 1750 $\mathrm{mm}$ (SE tree) are also shown as thin lines in the same figure. The calculated values were higher than the measured values before the fire spread from the ignited sofa to the adjacent sofa. The difference between the two calculated results was small because the radiation feedback was small at this stage.

The temperature of the vertical surface (outside of the armrest) of the sofa adjacent to the ignited sofa increased due to thermal radiation from the flame and smoke layer and reached the ignition temperature $\left(350{ }^{\circ} \mathrm{C}\right)$ at $90 \mathrm{~s}$, which was earlier than that in the experiment. This is because the actual fire spread process is affected by flame oscillation when the fire spreads by contact of the flame with the combustible surface. In addition, the calculation did not consider that the radiation flux to the sofa adjacent to the ignited sofa was partially blocked by the armrest of the ignited sofa. As the modeling these effects is difficult, the time to fire spread to each combustible was input to the model.

After the fire spread to the sofa adjacent to the ignited sofa, the calculated compartment temperature considering radiation feedback followed the experimental trends, such as the rapid increase in temperature. When radiation feedback was neglected, the increase in the compartment temperature was more gradual than that of the experiment.

After the fire spread to the three seater sofa, the calculation that included radiation feedback switched to a one-layer zone model from the two-layer zone model and became a ventilation-controlled fire. The compartment temperature decreased slightly because the temperature of the lower zone was low at that time. The compartment temperature was almost constant afterward and agreed well with the experiment. In the experiments, the fire was ventilation-controlled because flame ejection from the opening was observed. When radiation feedback was not considered, the compartment temperature continued to gradually increase and the fire became ventilation-controlled later than that in the experiment.

The calculated HRR of each combustible and total HRR are shown in Fig.10. The solid lines are the calculated results before flashover when radiation feedback was considered, and the dashed lines are those when radiation feedback was not considered. As to the HRR of the single seater sofa first ignited, the difference was small compared with single burning in open air. The difference became larger after the fire spread to the adjacent sofa because of radiation feedback from the flame of the adjacent sofa. The HRR of the adjacent sofa increased rapidly, and the maximum heat release rate was about 1.3 times the open burning. These differences caused the difference in the rate of rise of the compartment temperature after the fire spread to the second sofa.

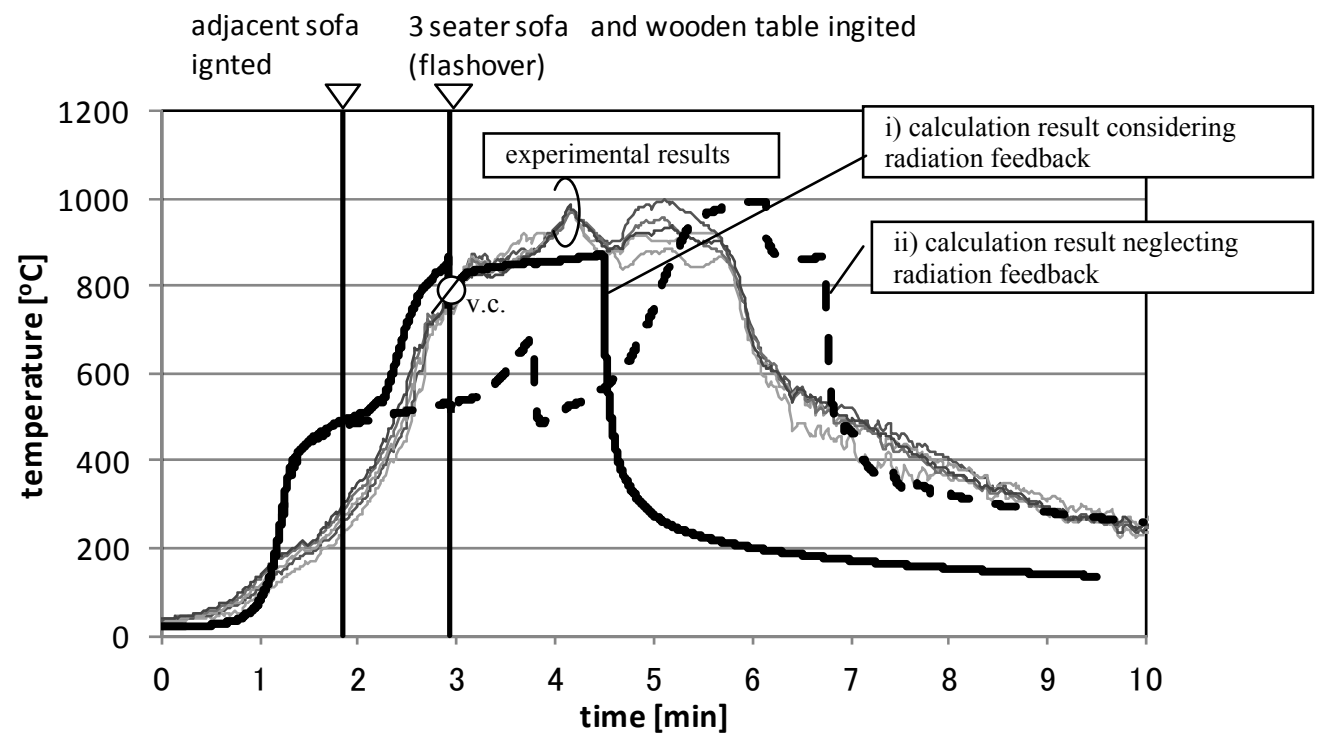

Fig.9 Comparison of compartment temperature of experiment and calculation 


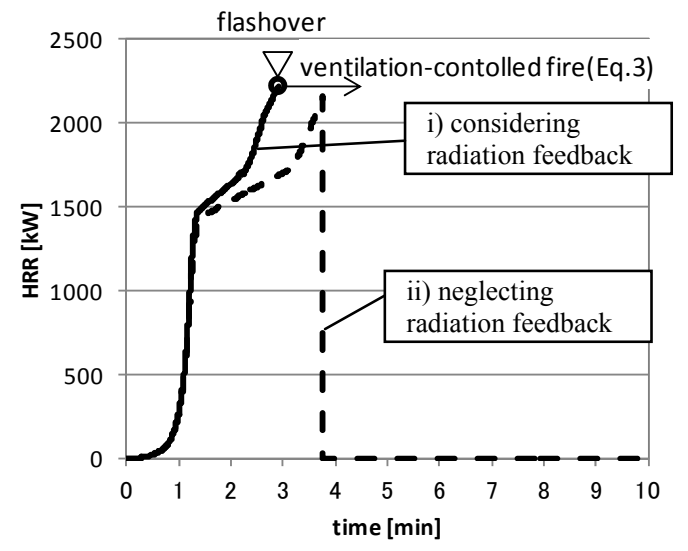

10a) Calculated HRR of the single sofa ignited at first

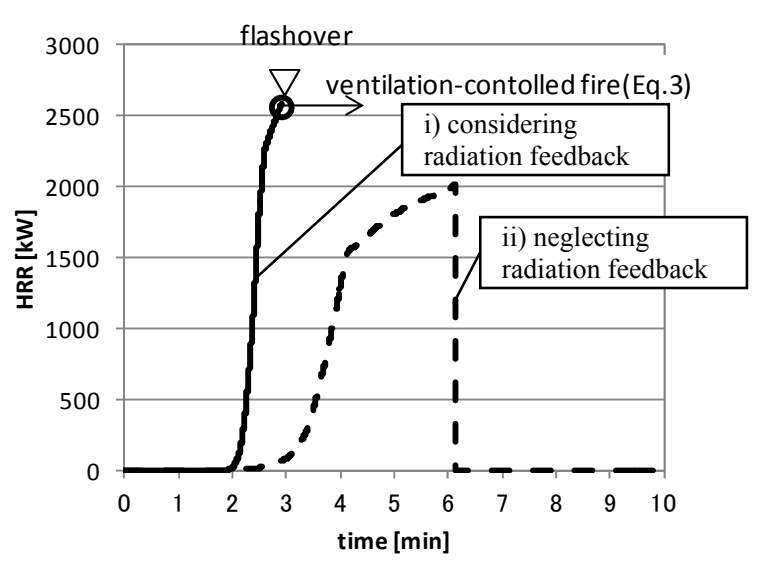

10b) Calculated HRR of the sofa adjacent to the ignited sofa

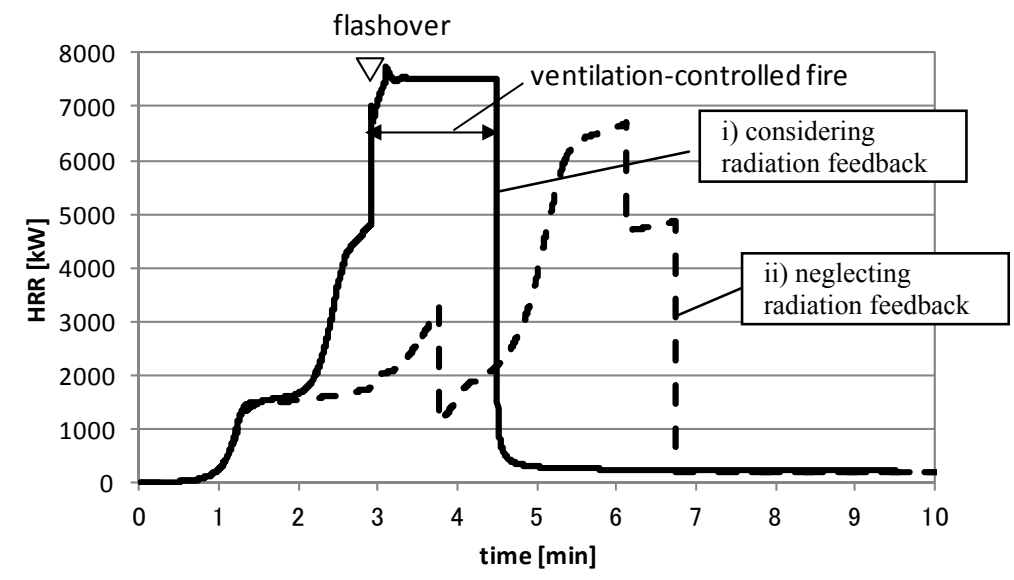

10c) Total HRR of each combustibles

Fig.10 Calculation results of heat release rate of combustibles

\section{CONCLUSIONS}

A calculation method has been developed to predict the burning behavior of a sofa in a compartment by using the HRR data measured in a furniture calorimeter. In order to include the effect of thermal feedback to burning items, a burning model was applied. The parameters for the model were estimated by fitting the model predictions to HRR measured in furniture calorimeter. The radiation heat flux from the flame was compared with measurements and found to be in good agreement. The effect of radiation feedback from the flame, smoke layer, and hot wall surfaces was considered by adding the corresponding terms into the calculated flame spread rates and HRR per unit area and so on. The burning model was combined with a zone compartment fire model to calculate smoke layer temperature and internal surface temperatures.

A compartment fire experiment was carried out incorporating two single seater sofas, one three seater sofa and one wooden table. The fire spread between objects was observed and compartment temperatures were measured. The calculated results were compared with experimentally measured temperatures. By comparison, it was shown that the increase of HRR in the compartment could be modeled by the proposed method, at least qualitatively. The rapid increase in the compartment temperature during the fire spread period was reproduced by the calculations. The increase of HRR of second and subsequent burning items may accelerate the fire spread process. 


\section{REFERENCES}

[1] Babrauskas V., "Heat Release Rates", THE SFPE Handbook of Fire Protection Engineering (3" ed), DiNenno P.J.(ed.), National Fire Protection Association, Quincy, MA02269, 2002, p3-1

[2] Architectural Institute of Japan, Recommendations for Design Fire Loads and Fire Actions in Buildings, 2013 (in Japanese)

[3] Sundstrom B.(ed.), Fire Safety of Upholstered Furniture - the final report on the CBUF research programme, 1995

[4] Utiskul Y., Quintiere J.G., "Theoretical and Experimental Study on Fully-Developed Compartment Fires", Proceedings of 7th Symposium Asia-Oceania Fire Science and Technology, 2007

[5] Goto D., Ohmiya Y., Delichatsios M.A., “A Model for Compartment Fire Behavior Incorporating Fire Growth and Vitiation", Fire Safety Science -- Proceedings of 10th International symposium, International Association for Fire Safety Science, 2011, pp.1249-1261, http://dx.doi.org/10.3801/IAFSS.FSS.10-1249

[6] Kim D.E., Kim G.C., Seo D.G., Kwon Y.J., “A study on the FDS Reliability Analysis for Scientific Fire Investigation", Summaries of Technical Papers of Annual Meeting, 2012, pp.145146, (in Japanese)

[7] Shintani Y., Nagaoka T., Deguchi Y., Harada K., (2013) A study on burning behavior of polyurethane foam exposed to radiant heat, Journal of Environmental Engineering: 78(685):241-247, (in Japanese). http://dx.doi.org/10.3130/aije.78.241

[8] Shintani Y., Harada K. (2009) A model for prediction of fire spread considering the effect of thermal feedback, Journal of Environmental Engineering: 74(641): 759-766, (in Japanese). http://dx.doi.org/10.3130/aije.74.759

[9] Tsukuda M., Harada K., Matsuyama K., Ohmiya Y., Norichika K., “A Prediction Model of Heat release rate history of Three-dimensional Combustibles Considering Thermal Feedback from Surroundings", Proceedings of JAFSE Annual Symposium, 2009, pp.82-83, (in Japanese)

[10] Tanaka T. and Yamada S.,(2004) BRI2002: Two Layer Zone Smoke Transport Model, Fire Science and Technology :23(1):1-44, http://dx.doi.org/10.3210/fst.23.1

[11] Thomas P.H., Research on Fire Using Models, Institute of Fire Engineer, Quarterly, 1961

[12] Quintiere, J., (1983) Measurement of Material Flame Spread Properties, Combustion Science and Technology :32:67-89, http://dx.doi.org/10.1080/00102208308923653

[13] Hasemi Y., Tokunaga T., (1984) Flame Geometry Effects on the Buoyant Plumes from Turbulent Diffusion Flames, Fire Science and Technology: 4(1) :15-26, http://dx.doi.org/10.3210/fst.4.15

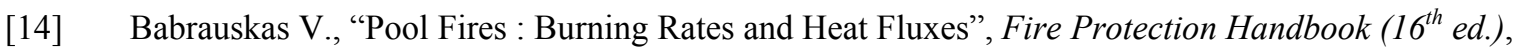
Cote A.E., Linville J.M. (ed.), National Fire Protection Association, 1986, p.21-36.

[15] Ohmiya Y., Satoh M., Tanaka T., Wakamatsu T., (1995) Burning rate of fuel in enclosure and generation limit of the external flame, Journal of Structural and Construction Engineering: 469: 149-158, (in Japanese). 